\title{
Bilateral visual loss due to a giant olfactory meningioma
}

This article was published in the following Dove Press journal:

Clinical Ophthalmology

2 March 2012

Number of times this article has been viewed

Jesse J Jung

Floyd A Warren

Ronit Kahanowicz

Department of Ophthalmology, New York University School of Medicine, New York, NY, USA
Correspondence: Jesse J Jung

Department of Ophthalmology, 462 First Avenue, NBV 5N 18, Bellevue Hospital Building, New York, NY I00I6, USA

Tel + I 2122636434

Fax + I 2I2 2638749

Email jung.jesse@gmail.com
Abstract: Olfactory groove meningiomas can present as large and insidious masses in the anterior cranial base. Due to their location and minimal clinical symptoms, these tumors can go undetected until they have grown extremely large. We present a clinical case and discuss the surgical management of a 63-year-old man who presented for an initial eye examination with bilateral visual loss for over 2 years due to a giant olfactory meningioma encompassing his entire frontal lobe and compressing on his optic nerves.

Keywords: olfactory groove meningioma, anterior skull base, optic atrophy, bilateral visual loss

\section{Introduction}

Olfactory groove meningiomas originate near the anterior cranial base, most commonly at the cribiform plate of the ethmoid bone, planum sphenoidale, and the frontosphenoidal suture. ${ }^{1}$ The incidence of olfactory groove meningioma is approximately $8 \%-14 \%$ of all intracranial meningiomas. ${ }^{2}$ Olfactory groove meningiomas are slow-growing tumors, often bilateral rather than unilateral, but asymmetrical in growth. They may produce progressive compression of the frontal lobes and project backward towards the sella, and if large enough, they can affect vision by compressing the optic nerve and chiasm. ${ }^{3}$ We present a case of a giant olfactory groove meningioma encompassing the entire frontal lobe and compressing the optic nerves and chiasm, and causing bilateral visual loss.

\section{Case report}

A 63-year-old man presented to the eye clinic with complaints of extremely poor vision and intermittent chronic headaches for over 2.5 years. He reported that his symptoms worsened gradually over this time period, and he denied any history of ocular trauma. He had no previous ocular history besides requiring correction for presbyopia. His medical history included well-controlled hypertension and he denied any family history of ocular or systemic disease.

On presentation, his vision was hand motion and light perception in the right and left eyes, respectively. Slit-lamp examination was significant for a horizontal beating nystagmus when attempting to fixate. Pupils were minimally reactive, with a relative afferent pupillary defect in the left eye. Intraocular pressure measured by applanation was $14 \mathrm{mmHg}$ in both eyes. Dilated fundus examination revealed a cup-to-disc ratio of 0.4 and bilateral optic nerve head pallor, greater temporally, and no signs of disc edema. Of note, on neurologic examination, the patient also reported a decreased 
sense of smell but no other signs of cranial nerve or systemic focal deficits.

An emergent noncontrast computerized tomography (CT) image of the head and orbits (Figure 1) revealed a $10.0 \times 7.1 \mathrm{~cm}$ hyperdense partially calcified mass extending from the planum sphenoidale to the midfrontal convexity with signs of bilateral optic nerve compression. Magnetic resonance imaging with and without intravenous gadolinium of the brain and orbits (Figure 2A and B) further delineated the CT findings and highlighted a large avidly enhancing midline extra-axial mass within the frontal region measuring approximately $9.4 \mathrm{~cm} \times 6.9 \mathrm{~cm}$ in axial dimension, consistent with a meningioma. The mass extended inferiorly to the cribiform plate and into the sellar/suprasellar cisterns, and compressed the optic chiasm and bilateral intracranial optic nerves. The patient underwent angiography and embolization followed by subfrontal lobe craniotomy with tumor resection and pericranial graft. Surgical tissue pathology confirmed the diagnosis as an olfactory groove meningioma.

At the one-week follow-up after surgery, his vision improved to counting fingers at three feet and hand motion in the right and left eyes, respectively. The patient reported being able to see bright red color in the right eye

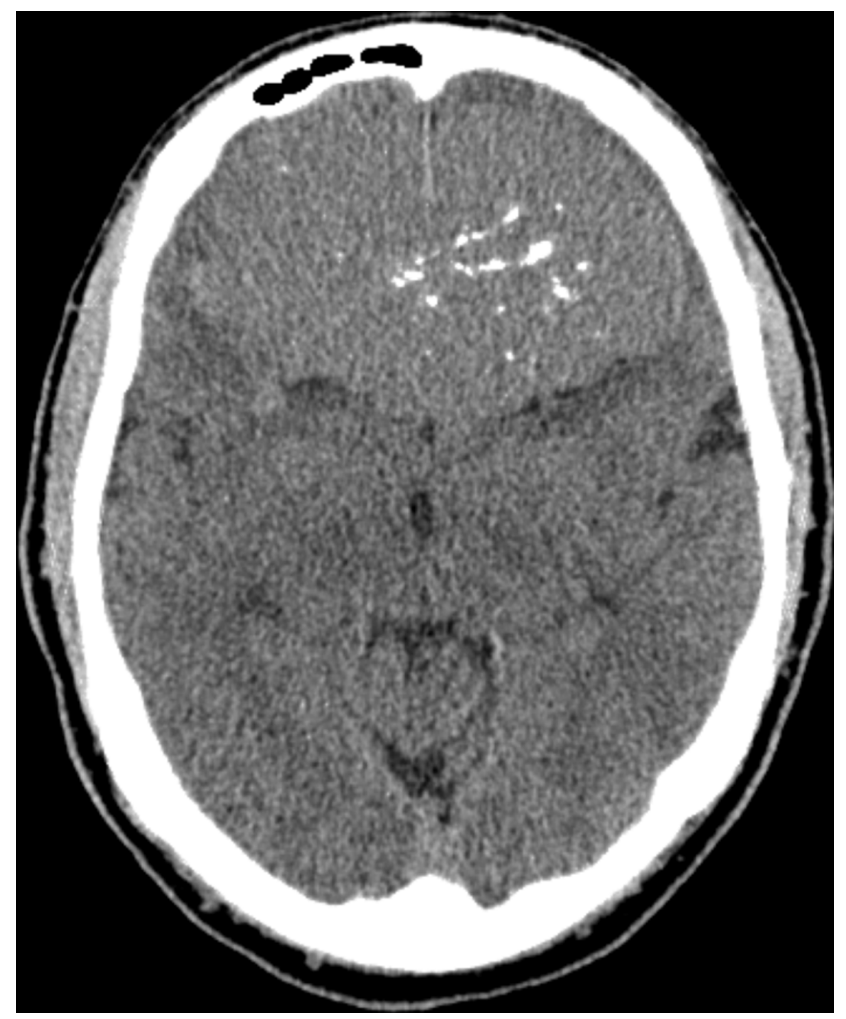

Figure I Noncontrast axial computed tomographic image initially identifying a giant, approximately $10 \mathrm{~cm}$ hyperdense partially calcified mass encompassing the entire frontal lobe.
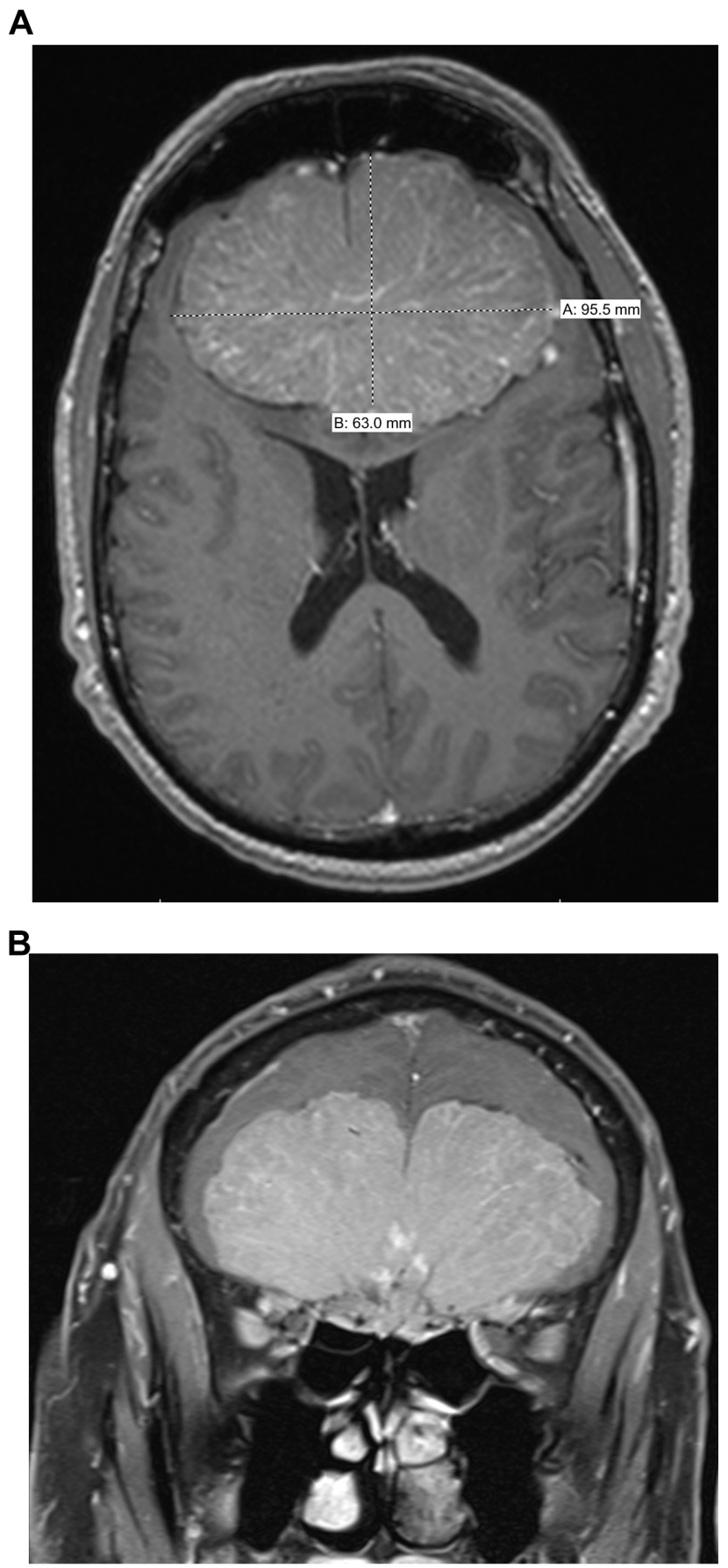

Figure 2 Contrast-enhanced TI axial (A) and noncontrast TI fat-suppressed coronal (B) magnetic resonance image revealing a large avidly enhancing midline extra-axial mass within the frontal region compressing the region of the optic chiasm and bilateral intracranial optic nerves.

by red saturation but was unable to complete the Ishihara color plates. Slit-lamp examination showed no signs of nystagmus with full saccades, but the patient had difficulty with pursuit. Pupils were minimally reactive, with a persistent afferent pupillary defect in the left eye. Postoperative magnetic resonance imaging of the brain with intravenous gadolinium (Figure 3A and B) showed a postoperative cavity 


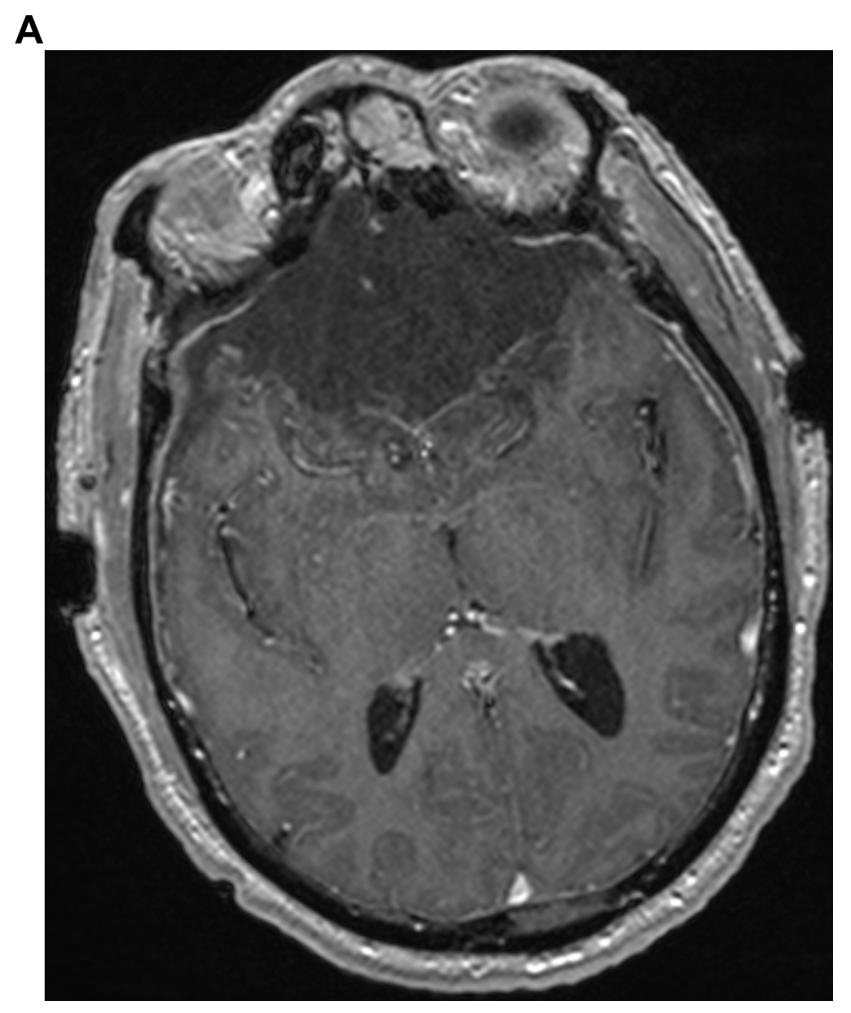

B

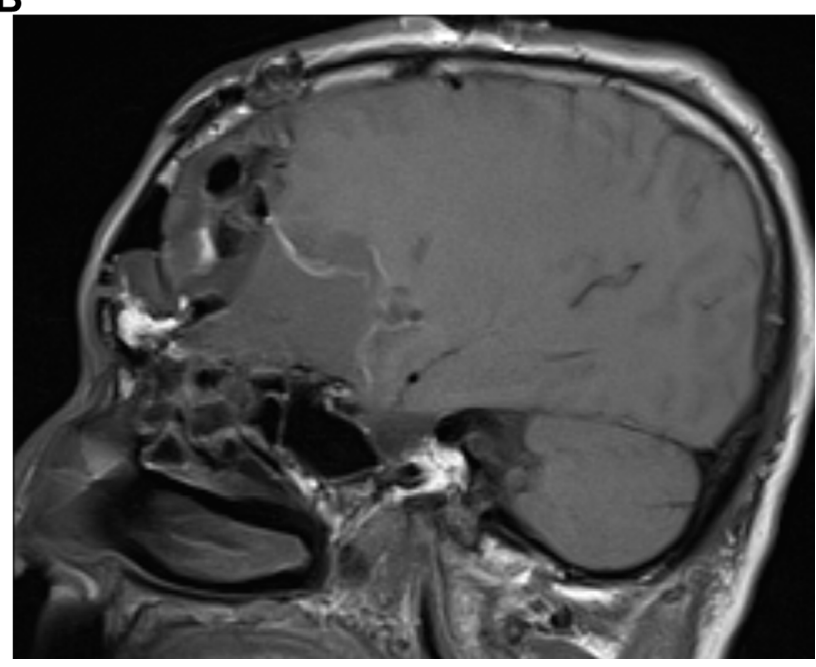

Figure 3 Contrast-enhanced TI axial (A) and sagittal (B) magnetic resonance image I week after bilateral frontal lobe craniotomy showing an extensive fluid and extraaxial pneumocephalus in the surgical bed without evidence of residual tumor.

with extensive fluid and extra-axial pneumocephalus in the surgical bed, without evidence of residual tumor.

\section{Discussion}

Olfactory groove meningiomas most commonly present with symptoms of headaches, anosmia, or even possibly personality changes. The anatomic location of the olfactory groove meningioma may cause prolonged psychiatric symptoms before the onset of more overt neurologic deficits. ${ }^{3}$ Due to these subtle symptoms prior to clinical presentation, olfactory groove meningiomas can grow insidiously large and present as one of the largest intracranial tumors. Tumor size has been categorized by neuroimaging evaluation. The classification includes small ( $0-2 \mathrm{~cm}$ in diameter), medium (2-4 cm diameter) large (4-6 cm diameter), and giant ( $>6 \mathrm{~cm}$ in diameter). A recent review of 59 consecutive patients with olfactory groove meningioma reported that 32 cases (54.2\%) and 11 cases (18.7\%) were of the large and giant classifications, respectively. ${ }^{3}$ Our current case with a giant olfactory groove meningioma measuring $9.4 \mathrm{~cm}$ in axial diameter emphasizes the large tumor burden that can present prior to neurologic symptoms.

Visual symptoms occur usually after an olfactory groove meningioma has reached a considerable size but can depend on their exact origin. Because olfactory groove meningiomas extend posteriorly, this extension can cause compression on one or both of the optic nerves or the chiasm, and may occur earlier in smaller tumors arising from the posterior half of the cribiform plate. ${ }^{4}$ Compression injury to the optic nerves may induce optic nerve head edema and eventually progress to optic atrophy and can also present as a Foster-Kennedy syndrome. The mechanism of injury in olfactory groove meningioma is due to the large size of the tumor, creating a downward pressure on the nerve and chiasm from above, unlike a suprasellar meningioma, which elevates the chiasm, thereby putting the crossed fibers on stretch and causing a bitemporal heminopsia with optic atrophy. ${ }^{4}$

According to several large retrospective case reviews of olfactory groove meningioma, the most common presenting symptom is headache. This presenting symptom of headaches is more commonly associated with large and giant tumors. ${ }^{3,4}$ In the current report, our patient reported gradually worsening headaches for over 2 years, along with his visual complaints, likely due to the giant nature of his olfactory groove meningioma. Interestingly, our patient also reported symptoms of anosmia, and although he did not report psychiatric or personality changes on initial history, after evaluation by psychiatry, it was found that his wife and family reported aggressive personality changes over the previous 2 years. These symptoms have been identified as the second and third most common presenting symptoms. ${ }^{3,4}$ Personality changes may be subtle, and may lead these patients to avoid ophthalmic care until their vision is extremely poor.

Treatment of olfactory groove meningioma is total surgical removal by a number of surgical techniques: a bifrontal approach with bifrontal polar lobectomy, a unilateral frontal approach with partial bifrontal lobectomy, a bifrontal approach without frontal lobectomy, a unilateral pterional-transylvian 
approach, a pterional approach, a frontorbital approach, a lateral supraorbital approach, to minimally invasive endoscopic techniques and craniofacial approaches. ${ }^{1-9}$ Each approach has both advantages and disadvantages, but according to the neurosurgical literature, bifrontal approaches allow for good exposure of giant olfactory groove meningioma and of the ethmoidal area, and facilitate good closure of the cranial base, minimizing cerebral spinal fluid leaks that are more common in subcranial approaches. ${ }^{1-3}$ Tumors with extension inferiorly into the paranasal sinus may not be amenable to bifrontal resection and may require a subcranial approach. This approach offers excellent access to the frontal, ethmoid, and sphenoid sinus and orbits, as well as allowing wide exposure for effective microdissection of tumor from the optic nerve and chiasm. ${ }^{1,5}$ Our patient underwent a bilateral subfrontal approach with complete resection of his giant olfactory groove meningioma. Due to the extensive size of his tumor, this approach was more successful in removing the entire tumor and decreasing the likelihood of recurrence.

The importance of this case report is that it provides an illustration of the optic nerve damage and visual loss that can occur with insidious tumors, such as an olfactory groove meningioma. These slow-growing, giant tumors can encompass the entire anterior skull base causing minimal symptoms, such as personality changes and anosmia, but the most significant presenting symptom can be vision loss. Ophthalmologists should be aware of these olfactory groove meningiomas because they can be successfully treated surgically and prevented from becoming life-threatening.

\section{Disclosure}

The authors have no proprietary or financial interest in any of the materials discussed in this work.

\section{References}

1. Pepper J, Hecht SL, Gebarski SS, Lin EM, Sullivan SE, Marentette LJ. Olfactory groove meningioma: discussion of clinical presentation and surgical outcomes following excision via the subcranial approach. Laryngoscope. 2011;121:2282-2289.

2. Nakamura M, Struck M, Roser F, Vorkapic P, Samii M. Olfactory groove meningiomas: clinical outcome and recurrence rates after tumor removal through the frontolateral and bifrontal approach. Neurosurgery. 2007;60:844-852.

3. Ciurea AV, Iencean SM, Risea RE, Brehar FM. Olfactory groove meningiomas. A retrospective study of 59 surgical cases. Neurosurg Rev. Sep 30, 2011. [Epub ahead of print.]

4. Bakay L, Cares HL. Olfactory meningiomas report on a series of twentyfive cases. Acta Neurochir (Wien). 1972;26:1-12.

5. Gazzeri R, Galarza M, Gazzeri G. Giant olfactory groove meningioma: ophthalmological and cognitive outcome after bifrontal microsurgical approach. Acta Neurochir (Wien). 2008;150:1117-1125.

6. Bassiouni H, Asgari S, Stolke D. Olfactory groove meningiomas: functional outcome in a sweries treated microsurgically. Acta Neurochir (Wien). 2007;149:109-121.

7. El-Bahy K. Validity of the frontolateral approach as a minimally invasive corridor for olfactory groove meningiomas. Acta Neurochir (Wien). 2009;141:1197-1205.

8. Halacq P, Moreau JJ, Fischer G, Beziat JL. Trans-sinusal frontal approach for olfactory groove meningiomas. Skull Base. 2001;11:35-46.

9. Hassler W, Zentner J. Surgical treatment of olfactory groove meningiomas using the pterional approach. Acta Neurochir (Wien). 1991;53:14-18.
Clinical Ophthalmology

\section{Publish your work in this journal}

Clinical Ophthalmology is an international, peer-reviewed journal covering all subspecialties within ophthalmology. Key topics include: Optometry; Visual science; Pharmacology and drug therapy in eye diseases; Basic Sciences; Primary and Secondary eye care; Patient Safety and Quality of Care Improvements. This journal is indexed on Submit your manuscript here: http://www.dovepress.com/clinical-ophthalmology-journal

\section{Dovepress}

PubMed Central and CAS, and is the official journal of The Society of Clinical Ophthalmology (SCO). The manuscript management system is completely online and includes a very quick and fair peer-review system, which is all easy to use. Visit http://www.dovepress.com/ testimonials.php to read real quotes from published authors. 